\title{
Effect of Sodium Carboxymethylcellulose Biopolymer on Sedimentation Properties of Trimagnesium, Tricalcium and Tristrontium Phosphates Precipitates
}

\section{IBOROMA, SD*; COOKEY, GA; OBUNWO, CC}

Department of Chemistry, Rivers State University, Port Harcourt, Nigeria

*Corresponding Author Email: daopuye.iboroma1@ust.edu.ng

\begin{abstract}
Sedimentation data of bioactive materials are essential in formulation of suspension with desirable requirements. Batch-wise precipitation and sedimentation tests were conducted to evaluate the effect of sodium carboxymethylcellulose (Na-CMC) biopolymer solution on the sedimentation properties (rate and compaction) of trimagnesium phosphate (TMP), tricalcium phosphate (TCP) and tristrontium phosphate (TSP) precipitates. Fixed volume $(1 \mathrm{ml})$ of different concentrations $(200 \mathrm{ppm}-2000 \mathrm{ppm})$ of $\mathrm{Na}-\mathrm{CMC}$ solution was mixed with fixed volume $(50 \mathrm{ml})$ of $0.5 \mathrm{M}$, $0.05 \mathrm{M} \mathrm{Na}_{3} \mathrm{PO}_{4}$ solutions. Accordingly, the resulting solutions were separately mixed with fixed volumes $(50 \mathrm{ml})$ of $0.5 \mathrm{M}$ $\mathrm{Mg}\left(\mathrm{NO}_{3}\right)_{2}, 0.05 \mathrm{M} \mathrm{CaCL}_{2}$ and $0.05 \mathrm{M} \mathrm{SrCL}_{2}$ solutions and settling of the precipitates formed monitored. The results showed that whereas for TCP, Na-CMC exhibited a curvilinear relationship with precipitate sedimentation, non-linear relationships were observed for TMP and TSP precipitates. Between 200ppm and 2000ppm of Na-CMC addition, sedimentation rate and compaction of TCP precipitate increased by $187 \%$ and $18.5 \%$, whereas for TMP and TSP precipitates, they increased by only $(19.89 \%$ and $1 \%)$ and $(30 \%$ and $0 \%)$, respectively. The results suggest that Na-CMC biopolymer is not the preferred suspending medium for suspension formulations containing TCP. For TMP and TSP precipitates, further study is needed in the light of the fact that magnesium and strontium resemble calcium.
\end{abstract}

\section{DOI: https://dx.doi.org/10.4314/jasem.v22i10.10}

Copyright: Copyright (C) 2018 Iboroma et al. This is an open access article distributed under the Creative Commons Attribution License (CCL), which permits unrestricted use, distribution, and reproduction in any medium, provided the original work is properly cited.

Dates: Received: 10 September 2018; Revised: 12 October 2018; Accepted: 29 October 2018

Keywords: sedimentation rate, compaction, precipitates, sodium carboxymethylcellulose

Sedimentation data of bioactive materials are dimensions indicative of their physical stability behaviours (Muralidhar et al., 2011) and are essential in achieving pharmaceutical suspension with desirable requirements (Manoharan et al., 2010). For hard tissue resuscitation and repair, injectable formulations of calcium and most recently magnesium and strontium substituted calcium phosphate are being developed as suspension drugs (Zhao et al., 2013; Rabelo-Neto et al., 2015; Wang \& Yeung, 2017). These drugs show sedimentation phenomena called compaction, over time, during storage and may form cake (Fatimi et al., 2007), causing difficulty in re-dispersion prior to use (Patel, 2010; Eraga et al., 2014). Suspending or stabilizing agents such as acacia, tragacanth and sodium carboxymethylcellulose ((Kadaji \& Betageri, 2011; Okorie \& Nwachukwu, 2011; Doye et al., 2017) are used to ameliorate physical stability drawbacks. Also, understanding of sedimentation behaviours (Muralidhar et al., 2011) as well as proper selection and control of precipitation conditions (Chawla et al., 2016) enable drug formulators avoid those irreversible aggregations.

Sedimentation behaviour of a suspension is interrelated to the size, according to Stokes, and concentration, according to Vesilind and Dick (Obunwo et al., 2017b), of the constituent particles. Larger particles settle faster than smaller ones. High particle concentration inhibits sedimentation of other particles. For precipitate suspension, Essien and Epke (1998) found the sedimentation behaviour dependent on the concentrations of reacting species. Reactant concentration affects both the size and the concentration of precipitate particles. The interaction of (suspending) medium with materials (ions, molecules, precipitates) in suspension can also influence the size, nature and concentration of particles formed, and thus the physical stability, too. Evaluation of effects of physical and chemical variables on sedimentation of insoluble inorganic substances in aqueous medium is an area of ongoing research. Studies may be of great importance and interest to suspension formulators. Literature search shows that nothing is recorded about the effect of sodium carboxymethylcellulose (Na-CMC) on sedimentation of the insoluble alkaline-earth metal phosphates precipitates. In this paper, the sedimentation properties (rate and compaction) of trimagnesium phosphate (TMP), tricalcium phosphate (TCP) and tristrontium phosphtate (TSP) precipitates, evaluated, by sedimenting fixed amounts of TMP, TCP and TSP precipitates with different concentrations of $\mathrm{Na}-\mathrm{CMC}$ solution, are presented.

\section{MATERIALS AND METHODS}

Analytical grade tribasic sodium phosphate, magnesium nitrate hexahydrate, calcium chloride, 
strontium chloride hexahydrate and sodium carboxymethylcellulose (Na-CMC), all from BDH Chemicals Limited, Poole, England, were used for the study. A thermostated precipitate sedimentation measurement apparatus was set-up in our laboratory using transparent (graduated) cylindrical tube, $3000 \mathrm{~cm}^{3}$ capacity beaker (as water-bath), temperature control heating mantle, magnetic stirrer and stirring rod. A digital chronometer was used for taking timely readings of the sedimentation tests.

Determination of Precipitate Sedimentation Characteristics: Batch-wise precipitation and sedimentation measurement procedures similar to those described by Obunwo et al., (2017a) were employed. Tests were carried out by adding fixed volume (1ml) of different concentrations (200ppm 2000ppm) of Na-CMC solution to fixed volumes $(50 \mathrm{ml})$ of $0.5 \mathrm{M}, \quad 0.05 \mathrm{M} \quad \mathrm{Na}_{3} \mathrm{PO}_{4}$ solutions. Accordingly, the resulting solutions were separately mixed with fixed volumes $(50 \mathrm{ml})$ of $0.5 \mathrm{M} \mathrm{MgNO}$, $0.05 \mathrm{M} \mathrm{CaCl} \mathrm{Ca}_{2}$ and $0.05 \mathrm{M} \mathrm{SrCl}_{2}$ solutions. The precipitate formed was immediately stirred for 2 minutes and allowed to stand. The downward displacement of the suspension zone was monitored visually, every minute, for 18 minutes (when the sedimentation was adjudged to be complete). The study was realized at the apparatus pre-set temperature of $30^{\circ} \mathrm{C}$. For every measurement, the sedimentation rate and compaction of the precipitate were determined. Tribasic metal phosphate precipitates (suspension) were formed by the ionic reaction between alkaline earth metal $(\mathrm{Me})$ and phosphate $(\mathrm{P})$ ions represented in equation 1 . The rate at which the suspension zone displaced (or moved) was used to measure the sedimentation rate (Equation 2). The ratio of the height of the suspension zone (or precipitate height) at equilibrium sedimentation to the sample height gave the compaction (Equation 3).

$$
\begin{aligned}
& \mathrm{M}^{2+}{ }_{(\mathrm{aq})}+\mathrm{PO}_{4}^{3-}{ }_{(\mathrm{aq})} \rightarrow \mathrm{M}_{3}\left(\mathrm{PO}_{4}\right)_{2(\mathrm{~s})} \\
& \text { Sedimentation Rate }(\mathrm{Rs})=\frac{H}{T}=\frac{-\left(h p_{i}-h p_{0}\right)}{t_{i}-t_{0}} \\
& \text { Compaction }=\frac{h p_{E S}}{h p_{0}}
\end{aligned}
$$

Where: $\mathrm{M}=$ magnesium, calcium or strontium in the precipitation process, $h p_{E S}=$ height of the precipitate at equilibrium sedimentation, $h p_{i}=$ height of the precipitate at a given time, $\mathrm{t}_{\mathrm{i}}$, and $\mathrm{hp}_{0}=$ height of the precipitate at time zero, $\mathrm{t}_{0}$.

\section{RESULTS AND DISCUSSION}

Results of sedimentation of TMP, TCP and TSP precipitates formed in different amounts of Na-CMC are displayed in Figure 1. For TMP precipitate (Figure 1A), profiles showed longer sedimentation times. For TCP precipitate (Figure 1B), profiles corresponding to 200ppm, 400ppm, 600ppm, 1000ppm and 1200ppm had longer sedimentation times while 1400ppm, 1600ppm, 1800ppm and 2000ppm exhibited shorter sedimentation times. However, for TSP precipitate (Figure 1C), profiles corresponding to all $\mathrm{Na}-\mathrm{CMC}$ concentrations showed shorter sedimentation times.

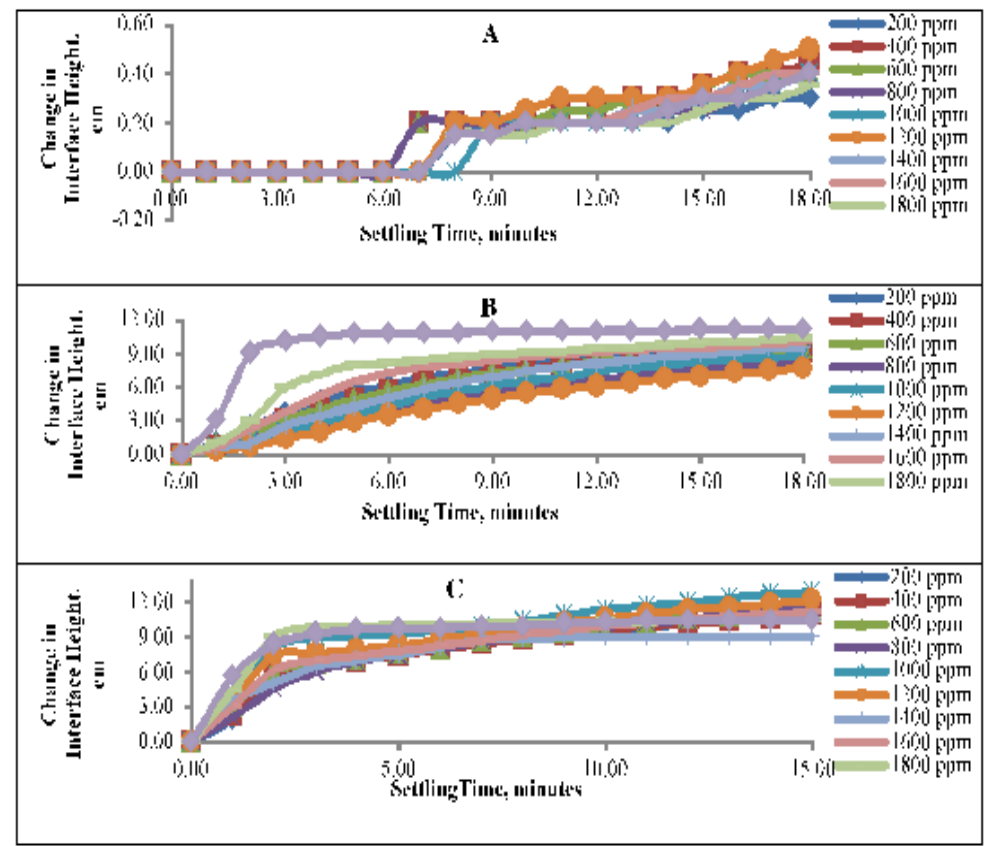

Fig 1: Residence times for TMP (A), TCP (B) and TSP (C) precipitates (Me:P = 50:50) formed with various amounts of Na-CMC at $30^{\circ} \mathrm{C}$.

The evaluated sedimentation rate results of TMP, TCP and TSP precipitates formed with various amounts of
$\mathrm{Na}-\mathrm{CMC}$ are displayed in Figure 2. The results showed that sedimentation rate of TMP and TSP precipitates 
are not significantly influenced by Na-CMC addition. Between 200ppm and 1200ppm of Na-CMC addition, sedimentation rates of TMP and TSP precipitates only increased from $0.0196 \mathrm{cmminute}^{-1}$ to $0.0235 \mathrm{cmminute}^{-}$ ${ }^{1}(19.89 \%)$ and from $2.36 \mathrm{cmminute}^{-1}$ to $3.06 \mathrm{cmminute}^{-}$ ${ }^{1}(30 \%)$, respectively. In contrast to TMP and TSP precipitates, Figure $2 \mathrm{~B}$ showed that sedimentation rate of TCP precipitate is markedly influenced by $\mathrm{Na}-\mathrm{CMC}$ addition. Sedimentation rate of TCP precipitate decreased slightly from $\left(1.26 \mathrm{cmminute}^{-1}\right.$ to $0.81 \mathrm{cmminute}^{-1}$ ) between $200 \mathrm{ppm}$ and $1400 \mathrm{ppm}$ of added Na-CMC. It rose sharply beyond $1400 \mathrm{ppm}$ to $3.63 \mathrm{cmminute}^{-1}$ at $2000 \mathrm{ppm}$. Sedimentation rate of TCP precipitate increased by $187 \%$ between $200 \mathrm{ppm}$ and 2000ppm Na-CMC addition.

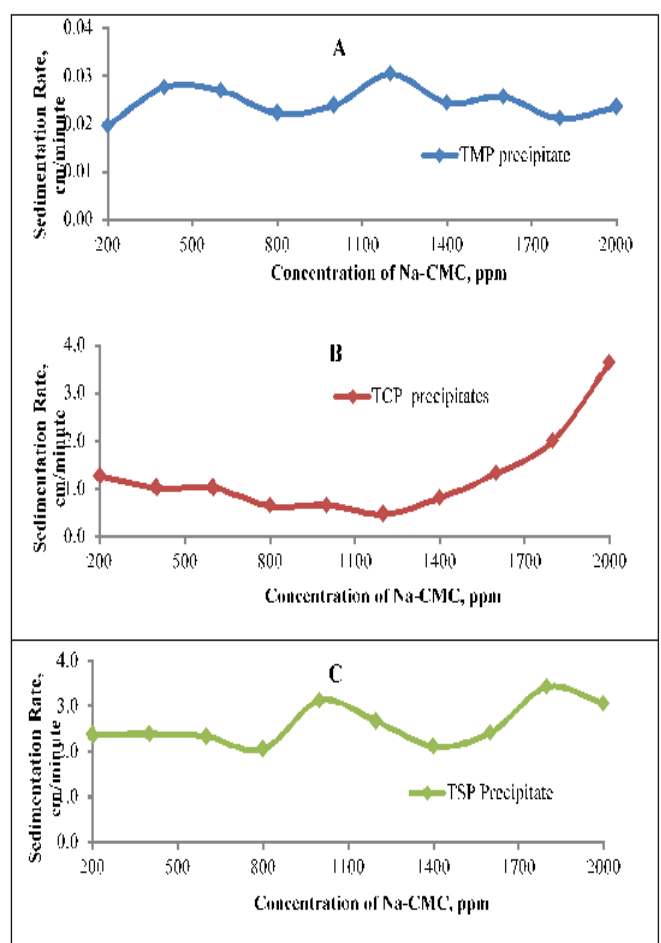

Fig 2: Sedimentation rates of TMP (A), TCP (B) and TSP (C) precipitates as function of added $\mathrm{Na}-\mathrm{CMC}$ at ambient temperature $\left(30^{\circ} \mathrm{C}\right)$.

Figure 3 showed the evaluated compaction results of TMP, TCP and TSP precipitates formed with different concentrations of Na-CMC solutions. The results showed that between 200ppm and 2000ppm of added Na-CMC solution, compactions of TMP and TSP precipitates were low. Between 200ppm and 2000ppm of Na-CMC addition, volume fraction of TMP precipitate only dropped from 0.965 to 0.960 (that is $1 \%$ increase in compaction). For TSP, precipitate volume fraction slightly increased from 0.426 to 0.456 ( $0 \%$ compaction). However, for TCP precipitate, compaction was high. Between 200ppm and 2000ppm of Na-CMC addition, volume fraction of TCP precipitate decreased from 0.508 to 0.414 (18.5\% increase in compaction).

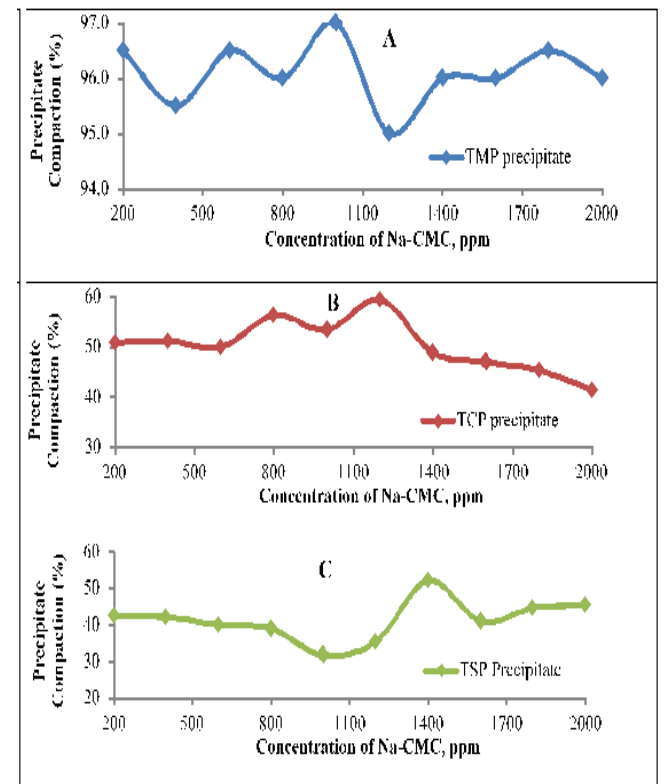

Fig 3: Compactions of TMP (A), TCP (B) and TSP (C) precipitates as function of added $\mathrm{Na}-\mathrm{CMC}$ at ambient temperature $\left(30^{\circ} \mathrm{C}\right)$.

By direct mixing, fixed amounts of TMP, TCP and TSP precipitates were formed and sedimented in presence of Na-CMC. The non-linear TMP precipitate sedimentation rate and compaction profiles displayed in Figures $2 \mathrm{~A}$ and 3A imply weak destabilization effect of Na-CMC on the TMP precipitate suspension. Similar inference can be adduced for TSP precipitate, according to Figures $2 \mathrm{C}$ and $3 \mathrm{C}$. On the other hand, the curvilinear sedimentation rate and compaction profiles of TCP precipitate illustrated in Figures $2 \mathrm{~B}$ and $3 \mathrm{~B}$, and which respectively gave $187 \%$ and $18.5 \%$ increases (between 200ppm and 2000ppm Na-CMC addition), indicate strong destabilization effect of $\mathrm{Na}$ CMC on the TCP precipitate suspension, possibly due to interaction of the precipitate particles with molecules of Na-CMC. Destabilization effect results when particles in suspension interact or react with its suspending medium. The mechanism of interaction is outside the context of this study. Nevertheless, ionpolymer complexation is possible whenever susceptible metal ion is in contact with complexable polymer (Ahemen et al., 2013; Crini and Flevet, 2017), and thus can alter medium viscosity. Hence, the suitability of Na-CMC biopolymer as suspending medium for magnesium, calcium and strontium phosphate compounds were followed using sedimentation properties of the latter in solutions of the former.

It may be stated here that the effect of $\mathrm{Na}-\mathrm{CMC}$ biopolymer on precipitate sedimentation depends on the nature of the metal (Me) ion involved. Affinity plays important role in chemical reactions. With a strong destabilizing effect on TCP precipitate, but of low influence on TMP and TSP precipitates, the results suggest the affinity between $\mathrm{Na}-\mathrm{CMC}$ molecule and calcium ion is high. It also suggests that $\mathrm{Na}-\mathrm{CMC}$ 
molecule has low affinity for magnesium and strontium ions. The revelation of this study and related study from Khaled \& Abdelbaki, (2012) affirm that $\mathrm{Na}-\mathrm{CMC}$ has high affinity for calcium ions, meaning also that it may not be a good suspending agent for formulations containing calcium. It has also been reported (Sultana et al., 2012; Mastropietro et al., 2013) that carboxyl groups of carboxyl-substituted methyl cellulose are particularly sensitive to calcium, aluminium and iron ions. According to the researchers, the complexation of the carboxyl group and calcium ions caused a reduction in medium viscosity, and thus high sedimentation rate.

Conclusion: This study has demonstrated the sedimentation behaviours of TMP, TCP and TSP precipitates in presence of $\mathrm{Na}-\mathrm{CMC}$ biopolymer. It was found that $\mathrm{Na}-\mathrm{CMC}$ biopolymer strongly destabilizes TCP precipitate suspension but exhibits zero effect on TMP and TSP precipitates. Therefore, the use of Na-CMC biopolymer as suspending agent in formulations containing calcium phosphate be done with caution to avoid compaction. However, with TMP and TSP precipitates further research efforts are needed in the light of the fact that magnesium and strontium resemble calcium.

\section{REFERENCES}

Ahemen, I; Meludu, O; Odoh, E (2013). Effect of Sodium Carboxymethylcellulose Concentration on the Photophysical Properties of Zinc Sulfide Nanoparticles. Brit. J. Appl. Sci. Technol. 3(4): 1228 - 1245.

Chawla, AK; Das, C; Sngh, P; Tiwari, M; Chaudhary, S (2016). Evaluation of physicochemical properties of aluminium phosphate gel to improve adjuvanticity. $J$. Cur. Res. Sci. 4(3): 104 - 110.

Crini, G; Flavet, P (2017). Metal removal from aqueous media by polymer-assisted ultrafiltration with chitosan. Arab. J .Chem. 10(2): 3826 - 3839.

Doye, P; Mena, T; Das, N (2017). Formulation and bioavailability parameters of pharmaceutical suspension. Intern. J. Cur. Pharm. Res. 9(3): 8 - 14.

Eraga, S; Iwuagwu, M; Adikwu, M (2014). Evaluation of the suspending properties of the co-precipitates of irvingia gabonesis gum and gelatin. Trop. J. Pharm. Res. 13(6): 843 - 848 .

Essien, IO; Ekpe, SD (1998). Determination of sedimentation rates of cobalt (II) insoluble compounds and absorption coefficient of the sedimenting particles using gamma radiation. J. Chem. Soc. Pak. 20(2): 120 124.

Fatimi, A; Tassin, J; Axelos, MA; Weiss, P (2010). The stability mechanism of an injectable calcium phosphate ceramic suspension. J. Mat. Sci. 21(6): 1799 - 1809.
Rabelo-Neto, JS; Knopf, TB; Fredel, MC; Olate, S; Moraes, PH (2015). Synthesis and characterization of calcium phosphate compounds with strontium and magnesium ionic substitutions. Intern. J. Morph. 33(3): 1189 1193.

Kadaji, VG; Betageri, GV (2011). Water soluble polymers for pharmaceutical applications. Polymers 3: 1972 2009.

Khaled, B; Abdelbaki, B (2012). Rheological and electrokinetic properties of carboxymethylcellulosewater dispersions in the presence of salts. Intern. J. Phy. Sci. 7(11): 1790 - 1798.

Manoharan, C; Basarkar, A; Singh, J (2010). General principles of suspensions. In: Kulshreshtha AK (ed) Pharmaceutical Suspensions: From Formulation to Development Springer-Verlag, New York, p.02.

Mastropietro, DJ; Nimroozi, R; Omidian, H (2013). Rheology in pharmaceutical formulations-A perspective. J. Dev. Drugs 2(2): 1 - 6.

Muralidhar, S; Bhanoji-Rao, ME; Chandrasekhara-Rao, G; Raviteja, P; Srinivasa, DS; Vasant, KP; Narayana, TV (2013). Studies on physical stability of rofecoxib oral Suspension using controlled flocculation approach. Intern. J. Innov. Pharm. Res. 4(2): 299 - 305.

Obunwo, CC; Iboroma, DS; Bagshaw, AP (2017a). Effects of physical variables on settling velocities of calcium and strontium phosphates in mother solution. J. Appl. Sci. Environ. Manage. 21(2): 307 - 311.

Obunwo, CC; Iboroma, DS; Cookey, GA (2017b). Influence of temperature and ion concentration on sedimentation characteristics of tricalcium phosphate (TCP) and tristrontium phosphate (TSP) Precipitates. J. Appl. Sci. Environ. Manage. 21(7), 1374- 1377.

Okorie, O; Nwachukwu, N (2011). Evaluation of the suspending properties of aloe barbadensis (aloe vera) gum in pharmaceutical suspensions. Intern. J. Pharm. Sci. Rev. Res. 6(2): 14 - 17.

Patel, MR (2010). Parenteral suspension: An overview. Int. J. Cur. Pharm. Res. 2(3): $04-13$.

Sultana, S; Islam, MR; Dafader, NC; Haque, ME; Nagasawa, N; Tamada, M (2012). Effect of mono- and divalent salts on the properties of carboxymethyl cellulose hydrogel under irradiadion technique. Intern. J. Chem. Sci. 10(2): 627 - 634.

Wang, W; Yeung, KWK (2017). Bone grafts and biomaterials substitutes for bone defects repairs: A review. Bioact. Mater. 2: 224 - 247.

Zhao, Y; Guo, D; Hou, S; Zhong, H; Yan, J; Zhang, C; Zhou, Y (2013). Porous allograft bone scaffolds: Doping with strontium. PLOS ONE 8(7): 1 - 10. 